\title{
COMUNICAÇÃO
}

\section{ASSOCIAÇÃO DE FASES MEIÓTICAS E ESTÁDIOS DOS MICRÓSPOROS COM CARACTERÍSTICAS MORFOLÓGICAS DE BOTÕES FLORAIS DE PIMENTÃO}

\author{
EDGARD AUGUSTO DE TOLEDO PICOLI ${ }^{1}$ \\ CARLOS ROBERTO DE CARVALHO ${ }^{2}$ \\ MIKLOS FÁRI ${ }^{3}$ \\ WAGNER CAMPOS OTONI ${ }^{4}$
}

\begin{abstract}
RESUMO - Fases meióticas e estádios de micrósporos de pimentão (Capsicum annuum L. cv. Azeth) foram determinados e associados com características morfológicas adotadas para a seleção de botões florais a serem utilizados na indução de androgênese. Plantas foram mantidas em casa-de-vegetação para coleta dos botões florais, que foram separados em seis classes de acordo com a relação de tamanho entre cálice e corola e presença de pigmentos nas anteras. As anteras foram fixadas em metanol: ácido acético na proporção de 3:1 e armazenadas a $-20^{\circ} \mathrm{C}$. Preparações citogenéticas desse material foram montadas pela técnica de dissociação e secagem ao ar e coradas com solução de Giemsa. As observações dos botões foram realizadas sob lupa e as
\end{abstract}

TERMOS PARA INDEXAÇÃO: Capsicum annuum, meiose, cultura de anteras.

preparações citogenéticas em microscópio ótico. Imagens dos botões florais, das anteras e das fases meióticas foram digitalizadas em computador para documentação. Variações de fases meióticas dentro de cada classe de botão floral foram observadas. Embora o critério de presença de antocianina na extremidade das anteras tenha sido aplicado para outras variedades, o mesmo não se mostrou adequado para a determinação do estádio de micrósporo neste estudo. As fases meióticas foram citogeneticamente identificadas; contudo, não foi possível estabelecer sua associação com as classes dos botões florais. Entretanto, botões com o tamanho de cálice coincidindo com o da corola apresentaram maior número de micrósporos em estádio adequado para a cultura de anteras.

\section{ASSOCIATION OF MEIOTIC PHASES AND MICROSPORE STAGES WITH MORPHOLOGICAL CHARACTERS OF FLORAL BUDS OF PEPPER}

\begin{abstract}
In the present study, morphological characters adopted for floral bud selection used for androgenesis induction were associated with pepper (Capsicum annuum L. cv. Azeth) meiotic phases and microspore stages. Floral buds were harvested from greenhouse-grown plants and separated into six classes according to size relationships between calyx and corolla, and anthocyanin pigmentation in anthers. After sorting by size, buds were fixed using a methanol: acetic acid $(3: 1)$ solution at $-20^{\circ} \mathrm{C}$. Cytogenetic
\end{abstract}

preparations were mounted using an adaptation of an air-drying technique and staining through a phosphate buffer Giemsa solution. Bud observations were accomplished under a stereo-microscope and the cytogenetic preparations in an optic microscope. Recordings of floral buds and meiotic phases were performed with an image digitizing computer system. Variations on the meiotic phases were observed within each class. Although the approach based on anthocyanin pigmentation on anthers has been applied

\footnotetext{
1. Engenheiro Agrônomo, M.Sc. em Genética e Melhoramento, UFV.

2. Professor do Departamento de Biologia Geral, UFV.

3. University of Debrecen, Centre of Agricultural Sciences, H-4032, Böszörményi út 138, Hungary.

4. Professor do Departamento de Biologia Vegetal ${ }^{(\bowtie)}$, Universidade Federal de Viçosa, Campus Universitário, 36570-000, Viçosa, MG. wotoni@ufv.br
} 
to another pepper varieties, it was not a reliable trait for determination of the microspore stage. Meiotic phases were citogeneticaly identified, although bud stage could not be associated with it. On the other hand, buds having the same calyx and corolla sizes presented a larger number of microspores in a suitable stage for anther culture.

INDEX TERMS: Capsicum annuum, meiosis, anther culture.

O gênero Capsicum $(2 \mathrm{n}=24)$ é largamente cultivado para uso como tempero e hortaliça, tanto nas zonas temperadas como nos trópicos. Neste último, espécies de Capsicum são muito importantes comercialmente, algumas talvez as mais importantes após o tomate (Leon, 1983). Isso tem motivado estudos em diversas áreas, como genética, melhoramento, evolução e biotecnologia (Kristiansen \& Andersen, 1993; Boiteux et al., 1993; Fontes, 1998). Do mesmo modo, relatos de alterações na meiose causadas por inseticidas (Devadas et al., 1986), fungicidas (Prakash et al., 1988), herbicidas (Reddy \& Rao, 1982a) e reguladores de crescimento (Reddy \& Rao, 1982b) são observados. O uso da citogenética e isoenzimas visando a estudos filogenéticos também se mostrou útil para Capsicum (Conicella et al., 1990).

A técnica de produção de di-haplóides por androgênese permite recuperar mutações recessivas e possui vantagens como economia de tempo e recursos de programas de melhoramento. Desse modo, a cultura de anteras tem sido utilizada em programas de melhoramento (Mitykó et al., 1996) e estudos genéticos de pimentão (Morrisson et al., 1986). Alguns estudos abordando a otimização e aplicações dessa tecnologia são relatados por Morrisson et al. (1986), Mitikó et al. (1995), Dolcet-Sainjuan et al. (1997) e Fernandes et al. (1999).

Segundo Luz (1995), para a obtenção de linhagens endogâmicas ou para produção de híbridos pelo melhoramento convencional, são necessárias 7 a 9 gerações para obtenção de uniformidade genotípica e fenotípica após o cruzamento intervarietal. Esse tempo pode ser reduzido pela obtenção de haplóides em gerações segregantes. Além disso, os haplóides possuem a vantagem de possuir apenas um alelo em cada loco gênico, fato que, após a duplicação do número de cromossomos, permite a produção de plantas homozigóticas para todos os locos, substituindo as gerações de autofecundação com o mesmo objetivo.

Vários aspectos influenciam o sucesso da cultura de anteras (Rakoczy-Trojanowska et al., 1997; Jain et al., 1996). O estádio uninucleado tardio de micrósporos é o mais adequado para a aplicação dessa técnica, sendo fundamental sua determinação. Nesse contexto, fa- ses meióticas e estádios de micrósporo de pimentão foram associados a características morfológicas adotadas para seleção de botões florais a serem utilizados na indução à androgênese.

Sementes de $C$. annuum cv. Azeth de foram germinadas e, 16 dias após a germinação, plântulas com foram transplantadas para vasos de PVC de dois litros contendo substrato (Plantmax), mantidos em casa-de-vegetação. Em seguida, com o desenvolvimento dos botões florais, amostras de diferentes tamanhos foram coletadas. Suas anteras foram retiradas, fixadas em ácido acético/metanol (1:3) e armazenadas a $-20^{\circ} \mathrm{C}$. Os botões foram separados em seis classes (Figura 1), observando-se a relação de tamanho entre cálice e corola, a forma da margem do cálice (Leon, 1983) e a presença de pigmentos nas anteras. Adotou-se como classe 1 quando o cálice estava fechado com dentes da borda se tocando. Para a classe 2, o cálice abrindo, com dentes não se tocando e sem visualização da corola, e corola despontando na classe 3 . Na classe 4, o cálice e a corola possuíam tamanhos semelhantes. Na classe 5, o cálice é pouco menor que corola e distintamente menor que corola na classe 6 . Preparações citogenéticas de anteras dessas classes de botões florais foram realizadas pela técnica de dissociação e secagem ao ar e coradas com solução de Giemsa em tampão fosfato com pH 6,8, adaptada de Carvalho \& Saraiva (1993). As observações dos botões foram realizadas sob lupa e as preparações citogenéticas em microscópio ótico (OLYMPUS BX60F) com objetiva de 100x. Imagens dos botões florais, das anteras e das fases meióticas foram digitalizadas em computador para documentação.

Diferentes fases da meiose foram observadas numa mesma classe de botão. Verificaram-se diferenças entre as fases meióticas de anteras de um mesmo botão; porém, a sincronia das figuras dentro de uma mesma antera foi observada. Cawood \& Jones (1980) verificaram um gradiente de desenvolvimento meiótico ao analisarem cortes transversais seqüenciais de anteras de tomate, fato semelhante ocorrendo também em Capsicum. Na diacinese/diplóteno, doze bivalentes foram observados unidos por quiasmas terminais e subterminais. A orientação dos doze bivalentes pode ser observada na Figura 2. 


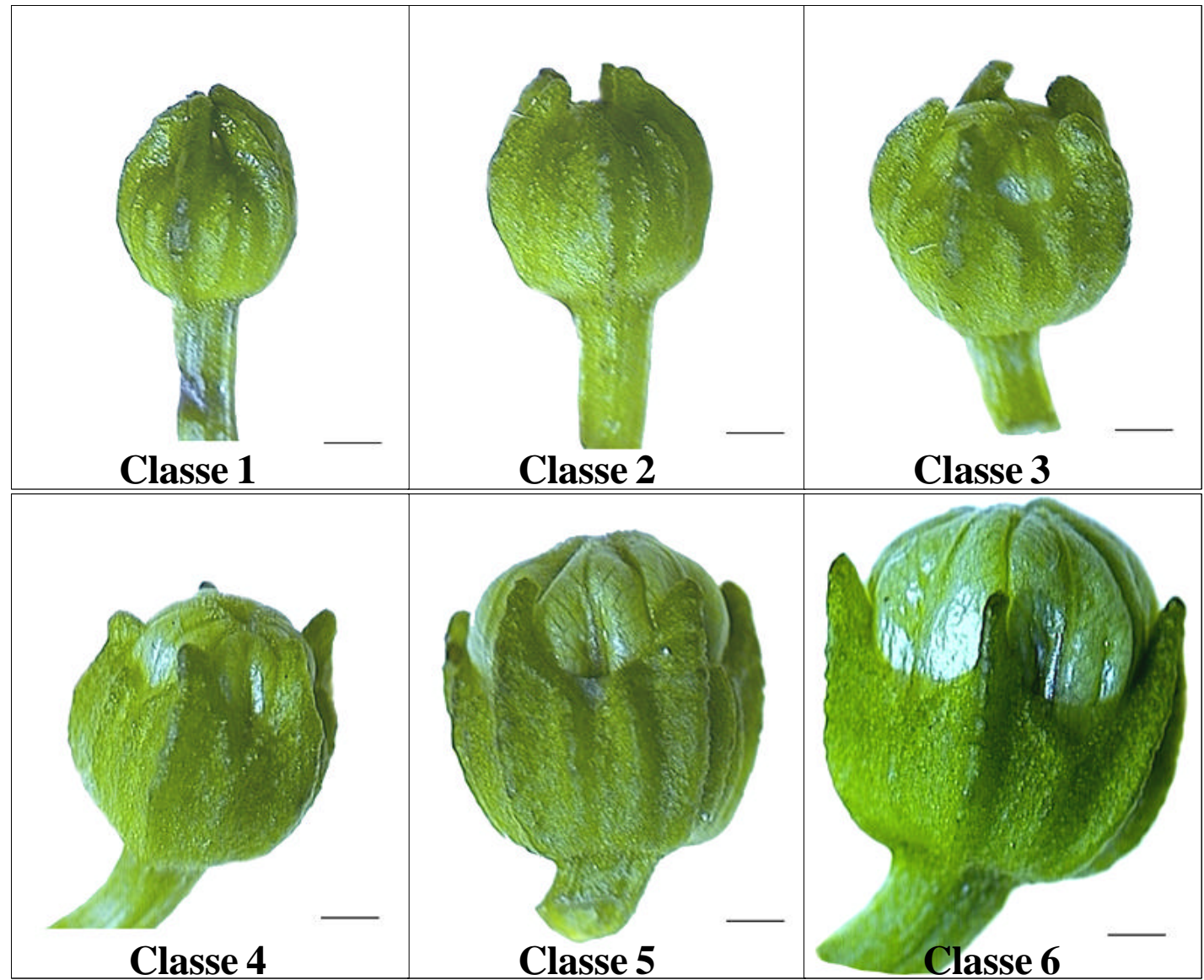

FIGURA 1 - Classes de botões florais de pimentão (Capsicum annuum cv. Azeth). (Barra = $1 \mathrm{~mm}$ ).

Para a maioria das espécies, o estádio de micrósporo uninucleado precoce é o mais adequado à cultura de anteras, de acordo com Stoher \& Zsuffa (1990), Hoekstra et al. (1992) e Sharma et al. (1993), citados por Atanassov et al. (1995). Em pimentão, o estádio uninucleado tardio, antes da primeira divisão mitótica do micrósporo, é o recomendado para a cultura de anteras (Luz et al., 1995; Dolcet-Sainjuan et al., 1997). Para a cultivar Azeth, esse último estádio foi observado quando os tamanhos do cálice e da corola coincidiam (Classe 4, Figura 1). Contudo, eventualmente, micrósporos mais tardios foram observados nessa classe, e anteras de botões mais jovens também apresentaram esse estádio. Ao contrário do sugerido por Luz et al. (1995) e Mitykó et al. (1996), a presença de antocianina na extremidade das anteras não foi um bom critério para determinação do estádio do micrósporo, por não coincidir com o estádio adequado para a cultivar estudada.
As condições de manejo das plantas podem alterar o processo da meiose, considerando que situações de estresse influenciam o mesmo. A relação entre a aparência do botão e o desenvolvimento dos micrósporos e/ou entre aparência das anteras e desenvolvimento dos micrósporos não é absoluta (Vagera, 1990). Segundo esse autor, desvios dessas relações ocorrem no cultivo das plantas doadoras sob condições de casa-devegetação, especialmente nos meses de inverno.

Ltifi \& Wenzel (1994) relataram interações genótipo-temperatura na androgênese de pimentão. Luz et al. (1995) obtiveram uma associação de estádio de botão floral e estádios de desenvolvimento de micrósporo mais acurados, sugerindo maior influência do genótipo ou do ambiente, ou ainda, maior rapidez no desenvolvimento da meiose no presente trabalho. Ainda, Kristiansen \& Andersen (1993) observaram que a idade e temperatura de crescimento da planta doadora influenciam a cultura de anteras.

Ciênc. agrotec., Lavras. V.27, n.3, p.708-713, maio/jun., 2003 


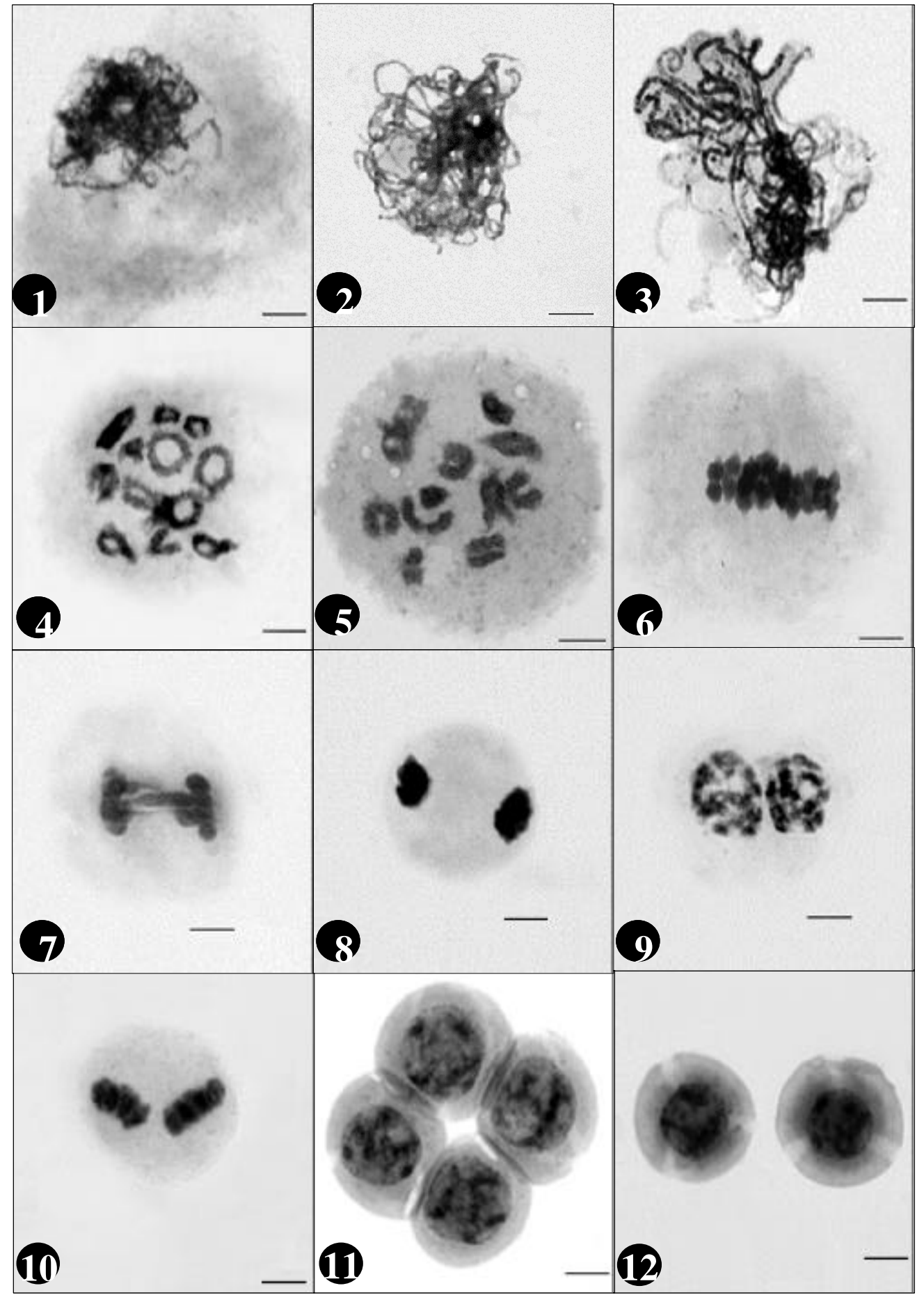

FIGURA 2 - Fases meióticas de pimentão (Capsicum annuum). Meiose I (1 a 8) e Meiose II (9 a 12) - Prófase I; 1 : Final de leptóteno, 2: zigóteno, 3: paquíteno, 4: diplóteno e 5:diacinese; 6: metáfase I, 7: anáfase I e 8: telófase I. 9: Prófase II, 10: metáfase II, 11: tétrade e 12: micrósporo (Barra $=5 \mu \mathrm{m})$. 
A distribuição das fases meióticas de acordo com as classes de botões foi a seguinte: Na classe 1, foram observadas todas as fases da meiose I. A classe 2 apresentou todas as fases partindo da metáfase I até grãos de pólen, enquanto na classe 3 , apenas da meiose II até grãos de pólen. Tétrades, micrósporos e grãos de pólen foram observados na classe 4 . As classes 5 e 6 apresentaram micrósporos e grãos de pólen, e apenas grãos de pólen, respectivamente Essa observação pode estar relacionada com a presença de um ou mais fatores que proveriam à célula em divisão condições ou sinais para prosseguir com a meiose. Essas observações sugerem uma coerência de desenvolvimento entre as fases. Esse desenvolvimento, porém, não segue de maneira rígida os padrões estabelecidos para as classes de botão floral.

A variação das fases meióticas e estádios de micrósporo encontrados pode ser resultado de possíveis alterações de fatores como temperatura, luz e estresses que as plantas tenham sofrido, o que poderia alterar o desenvolvimento da meiose. Assim, com esses resultados infere-se que um maior controle desses fatores deve ser realizado no que diz respeito ao estudo das fases meióticas. Essas informações podem contribuir para melhores resultados na cultura de anteras e na obtenção de fases específicas da meiose. As fases meióticas foram citogeneticamente identificadas (Figura 2); entretanto, não foi possível estabelecer associação entre fase e classes de desenvolvimento dos botões florais. Por outro lado, botões com o tamanho de cálice coincidindo com o da corola apresentaram maior número de micrósporos em estádio adequado para cultura de anteras.

Pelos resultados obtidos, pode-se concluir: a) todas as fases meióticas ocorrem em anteras dentro de uma mesma classe botão floral; b) para a cultivar Azeth, classe de botão adequado para cultura de anteras é quando os tamanhos do cálice e corola coincidem; c) a presença de antocianina na extremidade das anteras não é um bom critério para determinação do estádio do micrósporo para a cultivar estudada; d) apesar de as fases meióticas terem sido identificadas, não foram verificadas associações específicas com as classes de botão floral.

\section{AGRADECIMENTOS}

O presente trabalho foi desenvolvido em colaboração com o Agricultural Biotechnology Center (ABC, Gödöllö, Hungria). À Dra. Judit Mitykó e Dr. Atila Szász, pelo empenho na demonstração da técnica de obtenção de haplóides em pimentão e pela disponibilidade na continuidade dos trabalhos nessa parceria.

\section{REFERÊNCIAS BIBLIOGRÁFICAS}

ATANASSOV, A.; ZAGORSKA, N.; BOUADJIEV, P.; DJILIANOV, D. In vitro production of haploid plants. World Journal of Microbiology \& Biotechnology, Oxford, v. 11, p. 400-408, 1995.

BOITEUX, L. S.; NAGATA, T.; DUTRA, W. P.; FONSECA, M. E. N. Sources of resistance to tomato spotted wilt virus (TSWV) in cultivated and wild species of Capsicum. Euphytica, Wageningen, v. 67, p. 89-94, 1993.

CARVALHO, C. R. de; SARAIVA, L. S. An air-drying technique for maize chromosomes without enzymatic maceration. Biotechnic \& Histochemistry, Louisville, v. 68 , n. 3, p. 142-145, 1993.

CAWOOD, A. H.; JONES, J. K. Chromosome behavior during meiotic prophase in the Solanaceae. Chromosoma, Berlin, v. 80, p. 57-68, 1980.

CONICELLA, C.; ERRICO, A.; SACCARDO, F. Cytogenetic and isozyme studies of wild and cultivated Capsicum annuum. Genome, Ottawa, v. 33, n. 2, p. 279-282, 1990.

DEVADAS, N.; RAJAN, M. V.; SUBHASH, K. Comparative mutagenicity of four organophosphorous insecticides in meiotic system of red pepper. Cytologia, Tokyo, v. 51, p. 645-653, 1986.

DOLCET-SAINJUAN, R.; CLAVERIA, E.; HUERTA, A. Androgenesis in Capsicum annuum L. Effects of carbohydrate and carbon dioxide enrichment. Journal of the American Society for Horticultural Science, Alexandria, v. 122, n. 4, p. 468475, 1997.

FERNANDES, M. I. B. M.; SITVAL, A. L.; BRAMMER, S. P.; GRANDO, M. F. Haploidização: genética e melhoramento. In: TORRES, A. C.; CALDAS, L. S.; BUSO, J. A. (Eds.). Cultura de tecidos e transformação genética de plantas: Brasília, 1999. Brasília: EMBRAPA-SPI/CNPH, 1999. p. 613650.

FONTES, M. A. Morfogênese in vitro, isolamento e cultivo de protoplastos e transformação genética de pimentão (Capsicum sp.). 1998. 165 p. Dissertação

Ciênc. agrotec., Lavras. V.27, n.3, p.708-713, maio/jun., 2003 
(Mestrado em Botânica) - Universidade Federal de Viçosa, Viçosa.

JAIN, A. K.; SARKAR, A.; DATTA, R. K. Induction of haploid callus and embryogenesis in vitro cultured anthers of mulberry (Morus indica). Plant Cell, Tissue and Organ Culture, Dordrecht, v. 44, p. 133-147, 1996.

KRISTIANSEN, K.; ANDERSEN, S. B. Effects of donor plant temperature, photoperiod, and age on anther culture response of Capsicum annuum L. Euphytica, Wageningen, v. 67, p. 105-109, 1993.

LEON, J. Genetic resources of Capsicum: a global plain of action. Roma: Food and Agriculture Organization of the United Nations, 1983. 49 p.

LTIFI, A.; WENZEL, G. Anther culture of hot and sweet pepper (Capsicum annuum L.): influence of genotype and plant growth temperature. Capsicum and Eggplant Newsletter, [S.1.], v. 13, p. 74-77, 1994.

LUZ, J. M. Embriogênese somática in vitro em anteras de pimentão (Capsicum annuum L.). 1995.115 p. Tese (Doutorado) - Universidade Federal de Lavras, Lavras.

LUZ, J. M. Q.; SILVA, R.; DAVIDE, L. C.; PINTO, J. E. B. P. Relação entre os estádios de desenvolvimento dos micrósporos e as características morfológicas do botão floral em pimentão (Capsicum annuum L.). Ciência Rural, Santa Maria, v. 25, p. 385-388, 1995.

MITYKÓ, J.; ANDRÁSFALVY, A.; CSILLÉRY, G.; FÁRI, M. Anther-culture response in different genotypes and F1 hybrids of pepper (Capsicum annuum L.). Plant Breeding, Berlin, v. 114, p. 78-80, 1995.

MITYKÓ, J.; ANDRÁSFALVY, A.; FÁRI, M. Hungarian pepper cultivar breaks through traditional barriers in breeding practices. Hungarian Agricultural Research, Budapest, v. 1, p. 18-22, 1996.
MORRISSON, R. A.; KONING, R. E.; EVANS, D. A. Anther culture of an interspecific hybrid of Capsicum. Journal of Plant Physiology, Stuttgart, v. 126, p. 1-9, 1986.

PRAKASH, N. S.; LAKSHMI, N.; HARINI, I. Cytological effects of agricultural chemicals II: effects of fungicides "Bavistin" and "Deltan" on chilli (Capsicum annuum L.). Cytologia, Tokyo, v. 53, p. 709-715, 1988.

RAKOCZY-TROJANOWSKA, M.; SMIECH, M.; MALAPSZY, S. The influence of genotype and medium on rye (Secale cereale L.) anther culture. Plant Cell, Tissue and Organ Culture, Dordrecht, v. 48, p. 15-21, 1997.

REDDY, S. S.; RAO, G. M. Cytogenetic effects of agricultural chemicals. II: effects of herbicides "Lasso and Basagran" on chromosomal mechanism in relation to yield and yield components in chilli (Capsicum annuum L.). Cytologia, Tokyo, v. 47, n. 2, p. 257-267, 1982a.

REDDY, S. S.; RAO, G. M. Cytogenetic effects of agricultural chemicals. III: effects of hormones "Planofix and Lihocin" on chromosomal mechanism in relation to yield and yield components in chilli (Capsicum annuиm L.). Cytologia, Tokyo, v. 47, n. 2, p. 269-278, $1982 b$.

VAGERA, J. Pepper (Capsicum spp.): in vitro induction of haploids. In: BAJAJ, Y. P. S. Biotechnology in agriculture and forestry. [S.1.]: Springer Verlag, 1990. v. 12, p. 375-392. 